\title{
Projetos Integrados na Educação Infantil: interlaçando saberes
}

\section{Integrated Projects in Elementary School: interlacing knowledge}

Adriana Miritello Terahata é Doutora e mestre em Educação: Psicologia da Educação pela PUC/SP. Professora especialista em contação de histórias e mediação de leitura para Educação Infantil na Escola Lourenço Castanho.

Leila Monteiro é especialista em Educação Infantil pelo Centro de Formação da Escola da Vila. Pós-graduada em Arte Educação pelo Instituto Maria Antônia/USP. Professora especialista em arte para Educação Infantil na Escola Lourenço Castanho. Formadora e assessora de professores.

\section{Contato: leilam@lourencocastanho.com.br adrianat@lourencocastanho.com.br}

\section{Resumo}

0 presente texto tem por objetivo compartilhar uma experiência realizada no segundo semestre de 2014, com crianças da Educação Infantil, para a Mostra Cultural em uma escola de ensino particular do município de São Paulo. 0 projeto ${ }^{1}$ integrou as áreas de artes, contação de histórias e música, possibilitando a vivência simultânea de diferentes linguagens e, desse modo, ampliando as experiências de aprendizagem das crianças envolvidas. Ao refletir sobre a ampliação das experiências de aprendizagem por meio da integração de diferentes linguagens, nos propomos também a uma reflexão sobre a ressignificação do tempo, do espaço e das interações dentro do ambiente escolar. Palavras-chave: educação infantil; projeto integrado; diferentes linguagens.

1. Além das autoras do presente texto, o projeto foi realizado pelas profas. Bruna Iza, de contação de histórias, Claudia Ferrari El Bayeh, de artes, e Renata Facury, de música, que idealizou a proposta. Também contou com a coordenação das profas. Fabiana Queirolo e Cristiane Mori. 


\begin{abstract}
This article shares an experience held in the second semester of 2014 for a cultural show of children from an elementary school in São Paulo. The project integrated arts, storytelling and musical areas making it possible to experience simultaneously all the different languages and, by doing so, expanding children's learning. The reflection on their expanded learning by the integration process between different languages enables a reflection on the resignification of time, space and interactions inside the school environment.

Keywords: elementary school, integrated Project, different languages.
\end{abstract}

\title{
Introdução
}

0 projeto relatado a seguir, de elaboração de uma Mostra Cultural, foi desenvolvido no segundo semestre de 2014, com crianças da Educação Infantil, em uma escola particular do município de São Paulo. Integrando as áreas de artes, contação de histórias e música, possibilitou a vivência simultânea de diferentes linguagens. Com propostas de exploração, reflexão e produção, os alunos mergulharam nessa experiência de aprendizagens múltiplas e exploração de um espaço para brincar, ouvir e criar.

Para o escritor Antonio Cícero (1996):

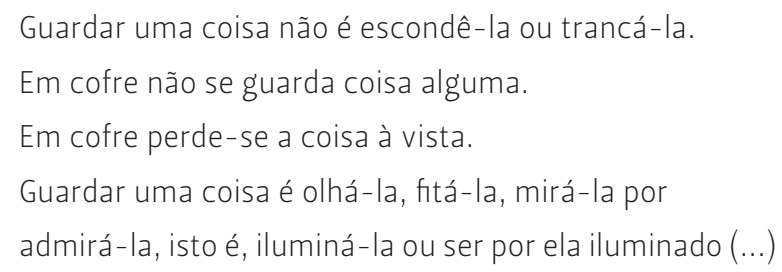

Nessa perspectiva de guardar, nos lançamos ao desafio de nos debruçar sobre a própria prática pedagógica e refletir sobre as possibilidades e desafios curriculares na Educação Infantil que uma experiência integrada evidenciou. Destacamos, no presente artigo, as relações com o espaço, o tempo e as interações que esse trabalho proporcionou às crianças e que são fundamentais para constituir uma prática pedagógica que amplie suas experiências de aprendizagem. 
Com isso, pretendemos colaborar com educadores e pesquisadores que pautam seus fazeres em um movimento constante de ação-reflexão-ação e almejam proporcionar às crianças experiências de aprendizagem menos fragmentadas.

\section{Os fios da história}

Antes de iniciar um bordado, uma costura, é fundamental escolher os fios que irão constituir suas formas. É preciso selecionar, entre tantos matizes, texturas, aqueles que mais se adequam ao projeto/tecido que se quer construir.

Em se tratando de Educação Infantil, nos guiamos pelos documentos oficiais que orientam a constituição dos currículos institucionais balizando alguns conceitos fundamentais como as concepções de infância, educação, aprendizagem, entre outros. Para melhor compreender a prática relatada, destacaremos alguns dos conceitos que fomentaram nosso planejamento.

0 primeiro deles refere-se ao que as Diretrizes Curriculares Nacionais da Educação Infantil assumem como experiências de aprendizagem, isto é, campos em que diferentes aprendizagens podem acontecer, dependendo das condições que irão constituir os ambientes de aprendizagens. Para a Orientação Curricular da escola:

\footnotetext{
uma experiência é algo que se vive e que possibilita/promove a construção de sentidos por parte do sujeito. Não se trata de simplesmente viver, fazer algo por fazer, ou meramente repetir algo, mas trata-se de poder colocar em relação referências internas, de sentir prazer (ou desprazer), de sentirse mais curioso, de sentir-se pertencendo etc. (OC, 2015, p.74).
}

Nessa perspectiva, se a escola constitui-se como locus privilegiado para diversificar e ampliar as experiências de aprendizagem das crianças, é fundamental que em seu currículo esteja prevista uma organização de tempo, espaço e situações didáticas em que as múltiplas interações sejam consideradas. Desse modo, como afirma Oliveira (2007), a organização curricular:

\footnotetext{
(...) concretiza situações nas quais as crianças se mostram exploradoras e são reconhecidas como interlocutoras inteligentes que constroem argumentos no confronto com situações estimulantes. Isso envolve respeitar ritmos, desejos e características do pensamento infantil (p. 51).
}

Para tanto, um segundo fio a ser destacado refere-se ao tempo no desenvolvimento das práticas pedagógicas na Educação Infantil. De acordo com as Orientações Curriculares da Escola 
para a Educação Infantil (2015, p. 74), as aprendizagens também são determinadas pela duração, periodicidade e sequência das atividades propostas e, mesmo que a criança ainda não opere com as noções temporais, considera-se fundamental que elas lidem com essas noções nas situações planejadas pelos educadores.

A prática aqui relatada se propôs a instaurar uma outra temporalidade no cotidiano das crianças. Aulas que frequentemente acontecem em momentos específicos, aulas de artes, de música e de contação de histórias aconteceram integradas. Isso possibilitou às crianças perceberem alguns aspectos importantes em relação ao tempo como, por exemplo, a simultaneidade dos fenômenos, isto é, em um mesmo tempo é possível ter múltiplas experiências, o que se aproxima muito mais da vida social da criança.

\section{De acordo com Zabala (1998):}

Muitas das boas intenções podem fracassar se o tempo não for considerado como uma autêntica variável nas mãos dos professores, para utilizá-la conforme as necessidades educacionais que se apresentem em cada momento (p. 134).

Nesse sentido, ao pretender proporcionar de modo integrado uma experiência com diferentes linguagens, se fazia fundamental que o tempo letivo também fosse integrado numa perspectiva de garantir a coerência da proposta prática que desejávamos desenvolver. Entendemos com isso que as crianças compreenderiam muito melhor e se apropriariam muito mais do trabalho se pudessem reconhecer no tempo proposto a integralidade da experiência.

Para a equipe, tal proposta foi desafiadora, pois estávamos acostumadas a planejar e executar nossas atividades separadamente, compartilhando muito mais nossas ideias do que nossos fazeres. Foi preciso rever o tempo/aula de todas as especialistas envolvidas e, consequentemente, de todos os docentes da instituição.

Um terceiro fio que gostaríamos de destacar refere-se à organização do espaço. Ao pretender proporcionar às crianças uma experiência integrada, tínhamos a intenção de constituir dentro do ambiente escolar um novo espaço de aprendizagem, um espaço em que as crianças também pudessem se deslocar do que já estavam habituadas e situá-las numa nova espacialidade. 
De acordo com as Orientações Curriculares da escola para Educação Infantil (2015):

À medida que explora os diferentes espaços da escola, considerando as intervenções dos parceiros mais experientes, a criança aprende sobre eles: sua localização, sua dimensão e seus significados (p. 75).

Ainda em relação às Orientações Curriculares da Escola para Educação Infantil, todos os ambientes institucionais se constituem espaços de aprendizagem desde que planejados intencionalmente pelos educadores em função das expectativas de aprendizagem, uma vez que podem oportunizar diferentes vivências. Ressalta-se ainda que nesse planejamento deve ser levada em consideração a composição estética do ambiente.

Desse modo, entendemos que na diversificação desses espaços pudemos ampliar as experiências de aprendizagem, tanto sobre o próprio espaço quanto sobre suas significações. Para Zabala (1998):

\footnotetext{
A necessidade de que o aluno viva num ambiente favorável para seu crescimento também inclui, e de maneira preferencial, o ambiente em que se deve se desenvolver. 0 estado de ânimo, o interesse e a motivação receberão a influência do meio físico da escola. Criar um clima e um ambiente de convivência, que favoreçam as aprendizagens, se converte numa necessidade da aprendizagem e, ao mesmo tempo, num objetivo de ensino. Ao mesmo tempo, as características dos conteúdos a serem trabalhados determinarão as necessidades espaciais (p. 132).
}

Nesse tempo-espaço, foram desenvolvidas atividades integrando as diferentes linguagens, prioritariamente artes visuais, música e contação de histórias. Assim, um quarto fio que gostaríamos de apresentar refere-se à perspectiva inter-relacional das diferentes linguagens envolvidas na presente proposta.

Ao apresentar as aulas integradas, compreendemos que as crianças também percebem as diferentes linguagens de modo integral, não fragmentadas. Isto quer dizer que, ao desenhar, por exemplo, as crianças expressam sua gestualidade; nas músicas e brincadeiras cantadas, elas exploram seus movimentos, a sonoridade e a estética das palavras, podendo brincar e se relacionar com elas de diversas maneiras.

Entendemos que as diferentes linguagens consideradas de modo contextualizado e não como componentes isolados contribuem para o desenvolvimento da curiosidade, da criação e da expressão da singularidade infantil. 
Dessa maneira, acreditamos que essa experiência integradaintegradora apresentou tanto uma nova percepção dos diferentes componentes curriculares artes, música e contação de histórias, como uma nova relação tempo-espaço dentro da escola. Essas perspectivas instauraram, consequentemente, novos padrões interacionais e, aqui, chegamos ao quinto e último fio desse tecido que gostaríamos de destacar: as interações.

Conforme as Diretrizes Curriculares Nacionais para Educação Infantil (2009) e as Orientações Curriculares da Escola para a Educação Infantil (2015), a interação deve se constituir como um dos eixos que organizam as experiências de aprendizagem. Assim, de acordo com documentação oficial da escola:

\section{a organização curricular deve cuidar para que haja diferentes composições interacionais, que prevejam momentos individuais e coletivos de trabalho, atividades em duplas, trios e outras possibilidades de organização do grupo.}

Também os parceiros interacionais devem ser variados, havendo interação criança e adulto, criança e criança da mesma idade e de diferentes idades (OC, p. 76).

Ao instituir uma prática integrada, estabelecemos novos padrões interacionais na medida em que as crianças puderam se relacionar com os professores especialistas de modo conjunto. Até então, as relações se davam de modo independente nos momentos das aulas específicas.

Além de compreender os diferentes modos de ser, de conduzir determinada prática, também puderam perceber um mesmo objeto, no caso o jornal, sob diversas perspectivas: como portador de texto, como brinquedo, ora como instrumento, como suporte para atividades plásticas e como, surpreendentemente, um novo espaço dentro da escola.

Uma vez escolhidos os fios, iniciamos o processo de tecelagem, de constituição de um novo tecido que, agora, compartilhamos com você, leitor.

\section{Trançando fios: o tecido}

E o tecido/projeto "Jornal: a fantástica fábrica de ideias" contou com atividades contemplando as aulas de artes, música e contação de histórias. Ao promover parcerias, foram interlaçados diferentes saberes, proporcionando aos alunos experiências de troca dos conteúdos específicos de cada área de conhecimento, a 
valorização das vivências coletivas, a exploração de novos espaços e materiais, assim como as experiências de trabalho coletivo.

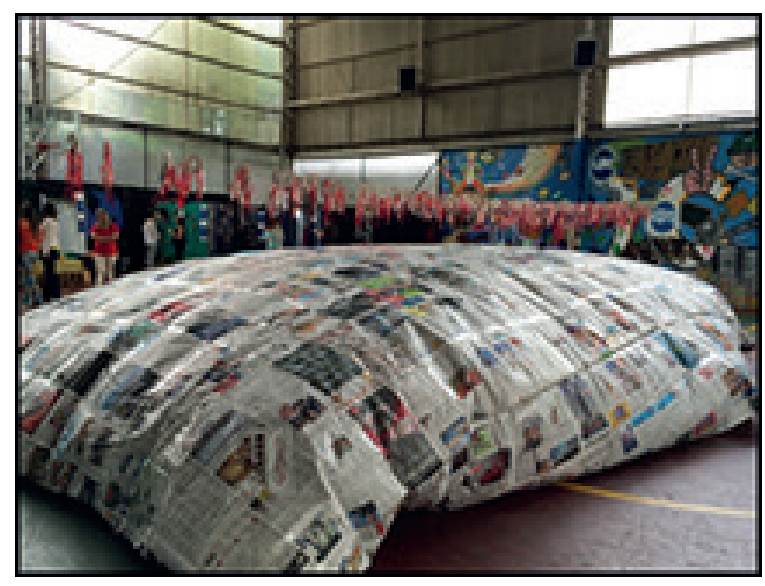

Figura 1 - "Travesseirão" montado na Mostra Cultural 2014

Criar um projeto é pensar com atenção em muitas etapas de trabalho. 0 espaço e a forma de agrupamento são algumas delas. Como uma escola ativa, buscou-se diversificar, e ao pensar em vivências coletivas sentiu-se a necessidade de criar um espaço onde as aulas se transformassem em novos momentos de prazer e descobertas. Surgiu, assim, a ideia de criar uma nova sala de aula. Um lugar nunca antes habitado, onde a imaginação poderia ser estimulada, os sons serem capturados e o aprender brincando aconteceria naturalmente.

Para a arte educadora Stela Barbieri (2012, p. 58):

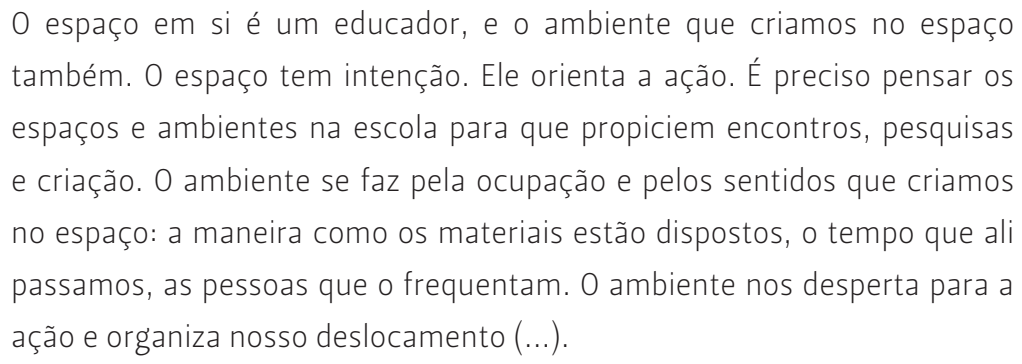

Buscando inspiração nas obras do artista Franklin Cassaro, que utiliza o jornal como matéria-prima para suas esculturas gigantes, escolheu-se experimentar um jeito de fazer do artista, e como preparação para o início do projeto as professoras construíram um "Travesseirão" de jornal. Colando as folhas com fita adesiva, a estrutura ficou com tamanho suficiente para receber uma sala de 16 alunos e cinco professoras.

O jornal tornou-se a linha condutora que teceria as atividades desse projeto, oferecendo a experiência de realizar diferentes propostas com um material já conhecido pelas crianças, mas 
nem sempre explorado com toda a potencialidade em atividades escolares.

Depois de inflado o "Travesseirão", os alunos chegaram para a primeira aula, curiosos por conhecer esse novo espaço. Os primeiros momentos foram de exploração, de descoberta, de troca de sentimentos entre eles. Alguns tentavam correr, outros deitavam para observar as imagens, mas todos eles interagiam com o espaço. E aos poucos a música começou, uma canção cantada de mansinho, feita para encantar, para rodopiar na ponta do pé. Sentados em roda, foram relatando suas impressões sobre o "Travesseirão", tirando dúvidas de como ele foi feito e como ficava inflado. A convite das professoras, foram contando suas vivências com o jornal, o uso que conheciam e o que acreditavam ser possível fazer.

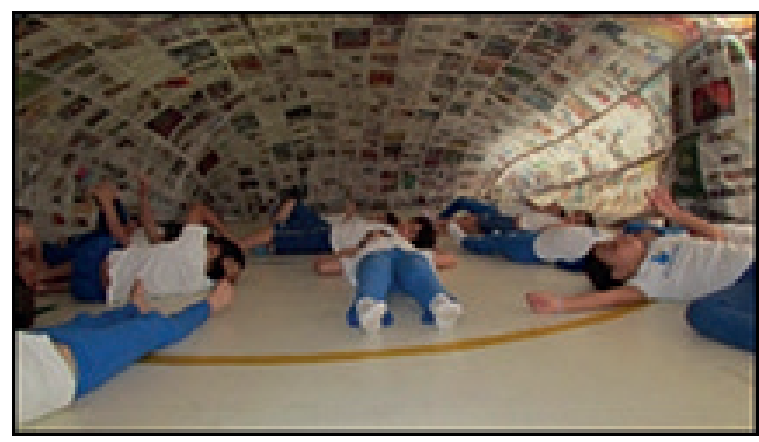

Figura 2 - Interior do "Travesseirão"

A atividade seguinte foi uma leitura de história utilizando o livro 0 Jornal, de Patricia Auerbach (Editora Brinque-Book). A narrativa sobre um menino que transforma as folhas de um jornal em diferentes brinquedos (espadas, barco, aviões) foi o ponto de partida para uma proposta em que os alunos também puderam criar seus próprios brinquedos. Cortando, amassando, rasgando, grudando com fita crepe, os pequenos "arteiros" criaram aviões, caminhões, bonecas, borboletas, espadas e muitos outros objetos alimentados por muita imaginação.

No ateliê, aconteceram diversas atividades de arte para experimentar o jornal como suporte de pintura, recorte, material para colagem e dobradura. Uma das propostas foi escolher imagens do jornal, pintar com nanquim o que desejavam ocultar e complementar com seus próprios desenhos.

Em algumas aulas integradas de artes e música, confeccionaram instrumentos de som. Um prato de papelão descartável foi utilizado como suporte no qual tiras de jornal e papel celofane foram 
coladas. Após seco, esse instrumento promovia um som parecido com o balanço das folhas nas árvores. Dentro do "Travesseirão" foram gravadas músicas cantadas e tocadas ao som desse novo instrumento.

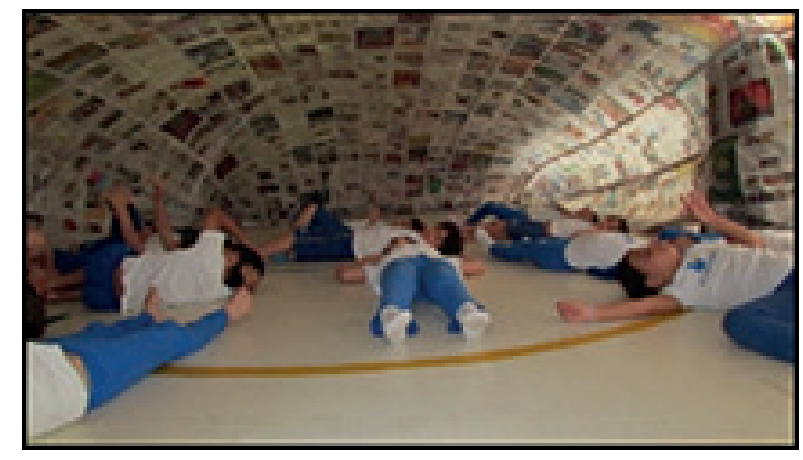

Figura 3 - Vivência com diferentes linguagens - música e artes

Os textos do jornal provocam curiosidade nas crianças que se encontram num cotidiano letrado, por isso não seria possível ignorar o interesse que demonstravam pelos tipos de letras ou as tirinhas de histórias. Com objetivo de trabalhar com o interesse das crianças, foram feitas atividades em que as letras se tornaram objeto de colagem ou interferência para um desenho. Na primeira, as crianças recortaram as letras e colaram criando figuras, dando contorno ao que desejavam representar, como flores, corações, aviões, borboletas, carros, rostos... Na segunda situação, a inicial do nome de cada criança foi colada numa folha em branco e elas a utilizavam como ponto de partida para um desenho de criação livre.

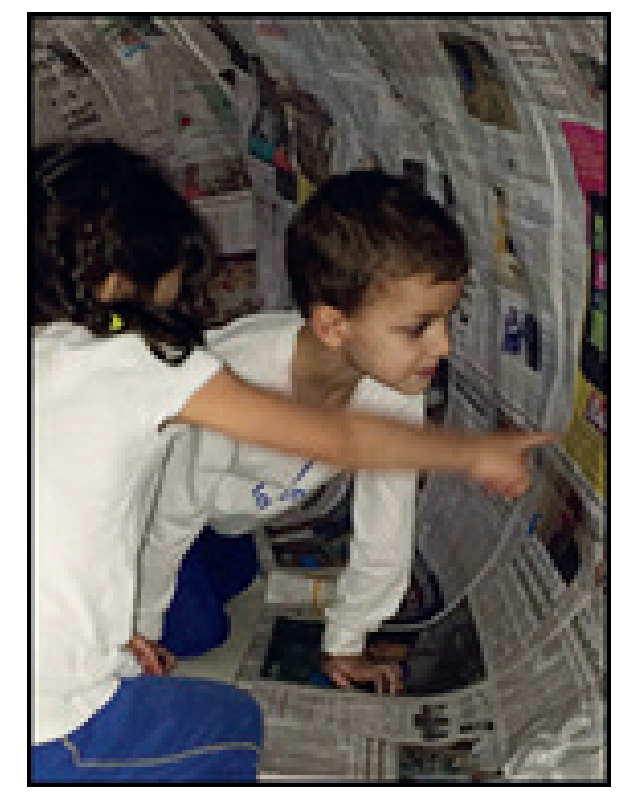

Figura 4 - Crianças observando-lendo as paredes do "Travesseirão" 
Outra atividade que divertiu muito as crianças foi a criação de onomatopeias. Após a leitura de tirinhas e conversa sobre a representação gráfica dos sons nesse tipo de texto, os alunos foram convidados a criar movimentos corporais e sons para representá-los. Essa brincadeira era filmada e os sons representando as ações escritos em balões nas aulas de arte.

No desenvolvimento desse projeto, as atividades se intercalaram entre as diferentes áreas, integrando-se e mostrando aos alunos que o caminho da aprendizagem é multidisciplinar. Foram situações em que as linguagens se encontraram, como representação por meio do desenho das músicas cantadas, criação de manchetes para os livros preferidos de cada grupo, dobradura de jornal para utilizar no mar de histórias, composições gráficas com imagens retiradas do jornal.

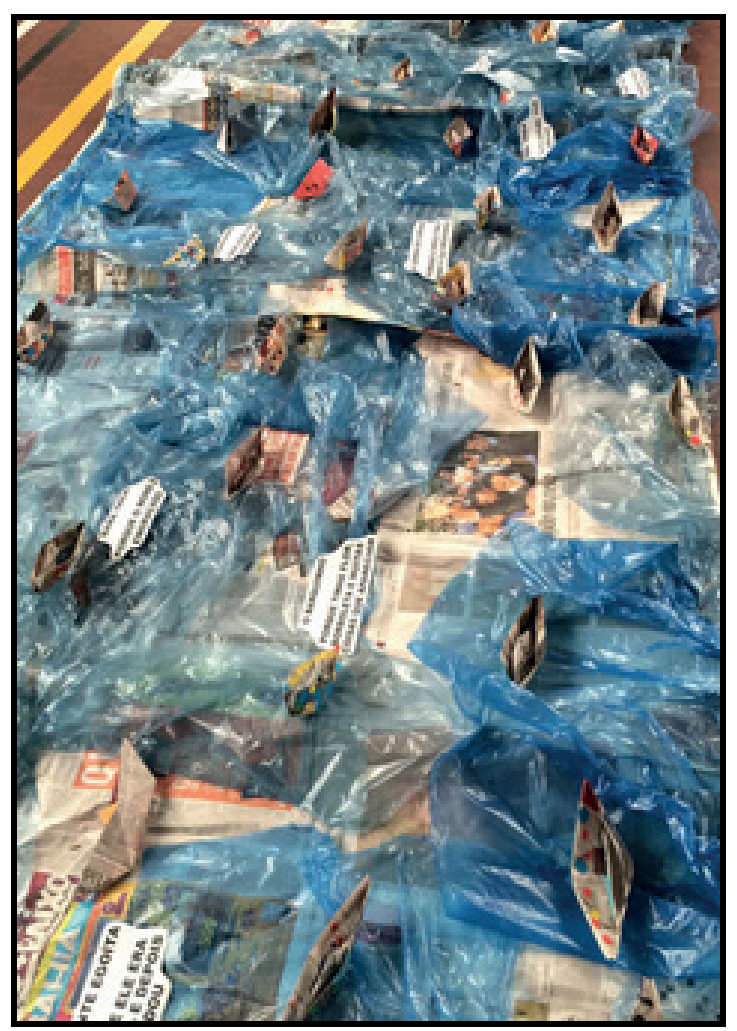

Figura 5 - Mar de histórias

\section{Costuras finais}

Impossível descrever neste relato os olhares de surpresa, os sorrisos e as expressões de euforia das crianças ao se depararem com um imenso travesseiro de jornal inflado na quadra da escola. 0 entrar de mansinho para não rasgar as paredes de jornal, a exploração dos textos e imagens que ainda podiam ser lidos, a 
acústica do ambiente que provocava a audição, a dança ao som de músicas tranquilas.... As aulas foram acontecendo assim, cada professora levando para o "Travesseirão" vivências combinadas e planejadas com o objetivo de ampliar a experiência vivida na escola.

Não existe começo, meio ou fim para uma aprendizagem. Somos seres múltiplos e é no olhar sensível ao outro que as propostas educacionais contemporâneas baseiam seu currículo, buscando respeitar o aluno de hoje e oferecendo a ele as melhores condições para aprender.

0 documento curricular para este projeto contava com inúmeras atividades, mas foram relatadas aqui algumas delas. A primeira foi escolhida por ser a proposta disparadora do trabalho, em que as crianças puderam falar de suas experiências, impressões e experimentar a exploração do espaço do "Travesseirão". As seguintes, para dar uma ideia da combinação entre as diferentes linguagens.

Este texto está por terminar, mas a sua intenção é de abertura ao diálogo. Abertura por se completar no modo de ser acolhido pelo leitor que se sentir desafiado a pensar/desenvolver propostas integradas na Educação Infantil.

Os fios que teceram essa trama estão fundamentados na admiração e respeito pela infância, pela equipe docente e gestora da escola que possibilitou tal experiência. No entanto, é preciso permanecer e continuar se debruçando atenciosamente sobre as múltiplas questões que tais práticas evidenciam, é preciso constituir um tecido que considere a diversidade de saberes, as particularidades de cada um, e que ele esteja costurado por um projeto de bem comum, é preciso COM-FIAR.

\section{REFERÊNCIAS}

ARENDT, H. Entre o passado e o futuro. Tradução de Mauro W. Barbosa. 5 ed. São Paulo: Perspectiva, 1968,[1964]. (Coleção Debates; v.64)

BRASIL. Ministério da Educação. Diretrizes Curriculares Nacionais para a Educação Infantil - 2009. Brasília: MEC / Secretaria de Educação Básica, 2009. Disponível em: http:// portal.mec.gov.br/index.php?option=com_content\&view $=a r$ ticle\&id $=12579 \% 3$ Aeducaca 0 -infantil\&ltemid $=859$ 
Referencial Curricular Nacional para a Educação Infantil. Brasília: MEC/SEF, 1998. Disponível em: http://portal. mec.gov.br/seb/arquivos/pdf/rcnei_vol1.pdf

BARBIERI, S. Interações: onde está a arte na infância? São Paulo: Blucher 2012.

CÍCERO, A. Guardar: poemas escolhidos. Rio de Janeiro: Editora Record, 1996, p. 337.

CRAIDY, C.; KAERCHER, G. E. Educação Infantil: pra que te quero? Porto Alegre: Artmed, 2001.

ESCOLA LOUREÇO CASTANHO. Proposta Curricular. São Paulo, 2015.

OLIVEIRA, Z. R. de. Educação Infantil: fundamentos e métodos. São Paulo: Cortez, 2007.

ZABALA, A. A prática educativa: como ensinar. Porto Alegre: ArtMed, 1998.

Recebido: 30/10/2015

Aceito: 17/12/2015 